\title{
Relative contributions of diet and sunlight to vitamin D state in the elderly
}

\author{
D E M LAWSON, ALISON A PAUL, ALISON E BLACK, T J COLE, A R MANDAL, M DAVIE
}

British Medical fournal, 1979, 2, 303-305

\section{Summary and conclusions}

In winter the vitamin $D$ state of elderly people may reach levels associated with osteomalacia, although the disease may not be clinically apparent. A statistical correlation was observed in a group of elderly subjects during the winter between dietary vitamin $D$ intake and vitamin $D$ state, but the intake was generally too low to make a biologically important contribution to maintaining vitamin $D$ concentrations. Ultraviolet light (UVL) is the primary determinant of vitamin $D$ state in summer and winter, in winter owing to the pools of vitamin $D$ built up during the previous summer.

Plasma concentrations of 25-hydroxy vitamin D (25-OHD) in winter of $15 \cdot 0-22.5 \mathrm{nmol} / 1(6-9 \mathrm{ng} / \mathrm{ml})$ require that the concentration in the previous summer was over $40 \mathrm{nmol} / 1$ (16 $\mathrm{ng} / \mathrm{ml})$. To maintain plasma concentrations in the elderly above those associated with osteomalacia a mean dietary vitamin $D$ intake of over $5 \mu \mathrm{g} /$ day is required. A more physiological approach, however, would be to increase exposure to UVL.

\section{Introduction}

Until fairly recently adequate measurement of vitamin D state was not possible, and hence the contribution of the two sources of vitamin $\mathrm{D}$ (diet and sunlight) towards maintaining this could be deduced only by empirical observation. Plasma contains the largest single pool of vitamin $\mathrm{D}$ activity ${ }^{1}$ in the form of 25-hydroxy vitamin D (25-OHD), ${ }^{2}$ and consequently vitamin $D$ state (and any factors affecting it) may be assessed by following the changes in the plasma concentrations of this metabolite. The value of ultraviolet light (UVL) in healing rickets was shown experimentally over 50 years ago, ${ }^{3}$ so that the ability of UVL to raise plasma $25-\mathrm{OHD}$ concentrations was not unexpected. ${ }^{4}$ Similarly the efficacy of vitamin $\mathrm{D}$ given by mouth has been shown experimentally in several studies, ${ }^{5-7}$ but the relatively large amount required to raise plasma $25-\mathrm{OHD}$ concentrations appreciably has not received the attention it deserves.

These studies, however, do not indicate the extent to which diet and UVL contribute to maintaining the vitamin D state in normal people. An indication of the importance of solar radiation is the seasonal variation in plasma $25-\mathrm{OHD}$ concentrations observed in several countries. ${ }^{8-11} \mathrm{We}^{7}$ have extended these observations and shown that the pronounced rise in plasma 25-OHD

\footnotetext{
University of Cambridge and Medical Research Council, Dunn Nutritional Laboratory, Cambridge CB4 1XJ

D E M LAWSON, PHD, member of scientific staff ALISON A PAUL, BSC, member of scientific staff ALISON E BLACK, BSC, senior research officer T J COLE, MA, BPHIL, member of scientific staff M DAVIE, MB, MRCP, Royal Society research fellow

Department of Geriatric Medicine, Sunderland General Hospital, Sunderland

A R MANDAL, MB, MRCP, senior consultant physician
}

concentrations during the early summer months is significantly correlated with the increase in hours of solar radiation through the same period. On the other hand, plasma 25-OHD concentrations are also correlated with dietary vitamin $\mathrm{D}$ intake, at least in subjects with a low vitamin $\mathrm{D}$ state. ${ }^{12}$ This last finding is unexpected in view of the small response of plasma 25-OHD concentrations to dietary supplementation with vitamin $\mathrm{D}$ at a level two or three times that present in the British diet. ${ }^{7}$ Even in subjects receiving 20 times the average daily intake the plasma 25-OHD concentrations were only within the range reached by British people during the summer.

In this study we have attempted to assess the relative importance of diet and solar radiation to vitamin $\mathrm{D}$ state in healthy elderly subjects, for whom dietary vitamin $\mathrm{D}$ might be expected to be particularly important. This study was carried out over 16 months, since the relative contributions of these two sources may change as the vitamin D state of the subjects changes.

\section{Subjects and methods}

We studied 12 men and 11 women, aged $72-86$ years, living at home in Sunderland (latitude $55^{\circ}$ ) and judged to be of better than average health for their age, who had taken part in a previous study ${ }^{13}$ of the elderly. Details of their clinical condition and their state with regard to other nutrients are reported elsewhere. ${ }^{14}$ Fourteen of the subjects had some degree of osteoarthritis, but none had osteomalacia. A blood sample was taken from each subject at the clinical examination, which occurred at three-monthly intervals over a 16-month period from July 1975 to October 1976 . The subjects were divided into three groups, one group being examined each month.

Plasma $25-\mathrm{OHD}$ concentrations were measured by a competitive protein-binding assay, ${ }^{15}$ and plasma calcium, phosphorus, and alkaline phosphatase concentrations by standard colorimetric assays using the Vickers Multichannel 300. Dietary vitamin D was estimated from daily records of all foods eaten over the whole period, supplemented at six-weekly intervals by one day's measurement of portions. Vitamin D intakes were calculated using food composition tables. ${ }^{16}{ }^{1}$; Vitamin D supplements, which were taken occasionally by only two subjects, made a negligible contribution to the overall dietary intake.

The time that subjects spent out of doors was assessed by an "outdoor score," in which up to 14 points were assigned to the number of times a week the subject went shopping or visiting or did gardening. Outings and holidays were also taken into account. These scores were . used to assess the relative variation in potential exposure to UVL out of doors. We could not, however, obtain a measure of the actual amount of time spent outside. Records of the local hours of sunlight were obtained from the Meteorological Office at Newcastle upon Tyne. Variations in ultraviolet radiation with time of year were obtained from published tables. ${ }^{18}$

Tests of significance of difference between means were made using Student's paired $t$ test, and correlations between two sets of values were assessed by Pearson's $r$ test.

\section{Results}

Plasma 25-OHD concentrations-The figure shows the variation in the plasma $25-\mathrm{OHD}$ concentrations throughout the 16 months, with the recorded weekly hours of sunshine for the area superimposed. Table I shows the average $25-\mathrm{OHD}$ concentrations as measured over each quarter. A highly significant difference in concentrations $(P<0.001)$ was found between the maximum values in the JulyAugust period and the minimum values in the December-May period. There were no significant differences between men and women. To 


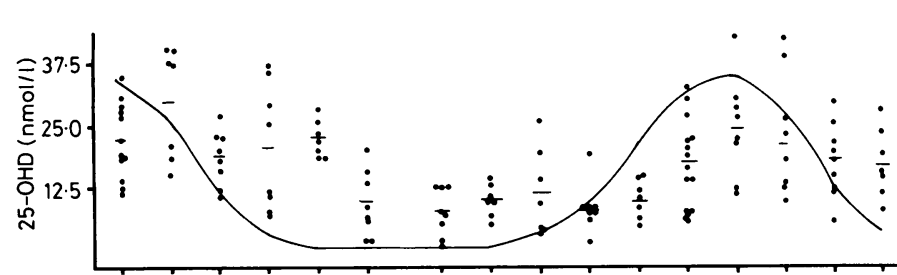

Jul Aug Sep Oct Nor Dec Jan Feb Mar Apr May Jun Jul Aug Sep Oct

Plasma 25-OHD concentrations in elderly subjects over 16 months from July 1975 to October 1976 . Solid line shows variation in recorded weekly hours of sunshine for this period.

Conversion: SI to traditional units-Plasma $25-\mathrm{OHD}: 1 \mathrm{nmol} / 1 \approx 0.4 \mathrm{ng} / \mathrm{ml}$.

TABLE I-Mean quarterly plasma 25-OHD concentrations (nmolll) in subjects studied

\begin{tabular}{cccc}
\hline Period & No of subjects & 25-OHD & SE of mean \\
\hline July Aug 1975 & 19 & $25 \cdot 3^{*} \dagger$ & $2 \cdot 25$ \\
Sept-Nov 1975 & 23 & $20 \cdot 5^{*}$ & 1.73 \\
Dec-Feb 1976 & 23 & $8 \cdot 8$ & $1 \cdot 05$ \\
Mar-May 1976 & 23 & $9 \cdot 5$ & 1.28 \\
Jun -July 1976 & 23 & $19 \cdot 3^{*}$ & 1.93 \\
Aug-Oct 1976 & 23 & $18 \cdot 5^{*}$ & $1 \cdot 78$ \\
\hline
\end{tabular}

*Significance of difference from Dec-Feb and Mar-May: $P<0.001$.

†Significance of difference from Aug-Oct 1976: $\mathrm{P}<0.001$.
Conversion: SI to traditional units-Plasma 25-OHD: $1 \mathrm{nmol} / 1 \approx 0.4 \mathrm{ng} / \mathrm{ml}$.

see whether summer 25-OHD concentrations influenced winter plasma concentrations we plotted the summer against the winter concentrations (six months later) in the same patient. The relation was logarithmic $(n=21, r=0.58, P<0.01)$ and showed that higher summer concentrations were associated with higher winter concentrations. The rise in concentration was significantly correlated with the increase in the hours of sunshine $(P<0.001)$ and UVL $(P<0.001)$ occurring throughout this period, even though the time of year at which the peaks occurred did not coincide. Calcium, phosphorus, and alkaline phosphatase concentrations were all within the normal ranges with little seasonal variation.

Outdoor score-The outdoor scores ranged from 4 to 13 in the men and 1 to 11 in the women, but the mean values ( 8 in the men and 7 in the women) were not significantly different. A subject who scored 1 went out of the house only once a week, for less than one hour, while subjects who scored 12 or 13 were out walking or gardening for over an hour most days of the week. Activities such as gardening or walking took five of the men but only one of the women outside more often in the summer than the winter. In general the patterns of outdoor activities such as shopping and visiting were little influenced by the season. As expected, the 25-OHD concentration in August-September and the outdoor score were significantly correlated $(n=23, r=0.623$, $\mathrm{P}<0.01$ ), but there was no correlation between $25-\mathrm{OHD}$ concentrations during December-April and outdoor score $(n=23, r=0.233)$. One woman with a fairly high winter $25-O H D$ concentration had one of the highest intakes of dietary vitamin $\mathrm{D}$ and yet almost never went out of doors. When she was omitted from the analysis a significant correlation was found between outdoor score and winter 25-OHD concentrations $(n=22, r=0.672, P<0.01)$.

Vitamin $D$ intakes - The average daily intake of vitamin $\mathrm{D}$ over the whole 16-month period was 2.4 ( \pm SD 1.3 ) $\mu \mathrm{g}$, ranging from 0.7 to $5.4 \mu \mathrm{g}$ between subjects. There was no seasonal variation. The six subjects with intakes above $3 \mu \mathrm{g}$ a day achieved this by frequently consuming foods with relatively high concentrations of vitamin $D$ (table II), in particular Ovaltine (which formed $65-85 \%$ of the intake

TABLE II-Percentages of vitamin $D$ intake provided by various foods. (Mean daily intake $2 \cdot 4 \mu \mathrm{g}$ (range $0 \cdot 7-5 \cdot 4 \mu \mathrm{g})$ )

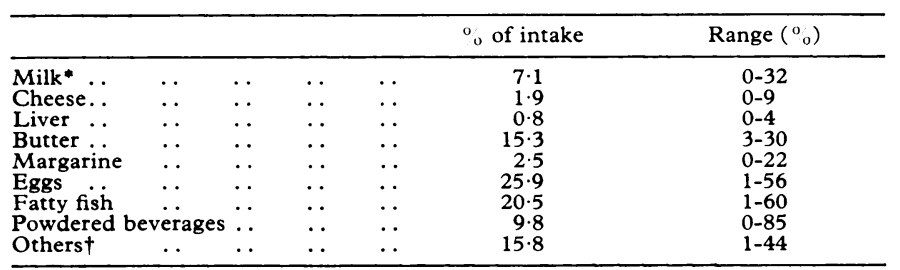

-Includes fortified evaporated milk.

tChiefly eggs and margarine in cereal products-for example, cakes and pies. in three subjects), fatty fish (kippers, canned sardines, and pilchards), and fortified evaporated milk (one subject). Only three subjects ate margarine regularly, and it contributed $13-22 \%$ of their intake; in the remaining subjects it provided negligible amounts. Eggs provided useful amounts $(0 \cdot 4-1.4 \mu \mathrm{g} /$ day) in 15 subjects. Vitamin D intake (average daily intake over the whole year) was not related to the summer plasma $25-\mathrm{OHD}$ concentration $(\mathrm{n}=23, \mathrm{r}=0 \cdot 15)$ but was significantly related to the winter concentration $(\mathrm{n}=23, \mathrm{r}=0.55, \mathrm{P}<0.02)$. The correlation between the 25-OHD concentration and the vitamin $\mathrm{D}$ intake in the period immediately preceding the time when the blood sample was taken wasthighest for the vitamin $D$ intake over the previous week ( $\mathrm{n}=79, \mathrm{r}=0.30 \quad \mathrm{P}<0.01)$, compared with the intake on the previous day $(r=0 \cdot 15)$ or month $(r=0 \cdot 21)$.

\section{Discussion}

Other investigators have drawn attention to the low vitamin D state of elderly people, ${ }^{19} 20$ but the low concentrations of ${ }_{\sigma}$ plasma 25-OHD actually reached in our subjects were nevertheless remarkable-for example, in the December-February period nine of the subjects had concentrations of under $7.5 \mathrm{nmol} / 1$ i ( $3.0 \mathrm{ng} / \mathrm{ml})$, which is within the range that osteomalacia may be $\vec{\infty}$ expected to develop. ${ }^{21}$ The maximum values reached in the $\mathrm{N}$ July-August period were only up to those at the lower end of the range of values found routinely in younger British people." Despite this, none of the subjects had clinical signs of osteomalacia, adding support to the warning that very low plasma 25-OHD concentrations cannot by themselves be taken to indicate inadequate vitamin $\mathrm{D}$ state. ${ }^{22}$

The present results clearly show that in the summer vitamin $\mathrm{D}$ state is primarily governed by the amount of exposure to solar $\vec{\theta}$ radiation, with dietary vitamin $D$ making only a small, almost negligible contribution. In winter at latitudes above $50^{\circ}$ vitamin $\mathrm{D}$ is not formed in the skin, and the body has to use that formed the previous summer or else obtain the vitamin from food. The findings that winter 25-OHD concentrations depend on the value reached the previous summer and are correlated with $\stackrel{\square}{\mathbb{Q}}$ outdoor exposure show that solar radiation is the primary factor $\overrightarrow{\vec{A}}$ controlling vitamin $\mathrm{D}$ state in winter. At the amounts normally $\frac{0}{3}$ ingested in the UK vitamin D can maintain plasma 25-OHD at $\frac{3}{2}$ only very low concentrations. In the present study the mean winter concentration was $8.8 \mathrm{nmol} / 1(3.5 \mathrm{ng} / \mathrm{ml})$, which must represent a maximum concentration of $25-\mathrm{OHD}$ sustained by the mean vitamin $\mathrm{D}$ intake of these subjects.

These findings also show that the subjects with the highest $\frac{5}{3}$ exposure to UVL have the highest plasma 25-OHD concentrations in both summer and winter. The relation found between $\frac{O}{3}$ summer and winter $25-\mathrm{OHD}$ concentrations shows that winter plasma concentrations of $15 \cdot 0-22 \cdot 5 \mathrm{nmol} / 1(6-9 \mathrm{ng} / \mathrm{ml})$ require $\frac{\circ}{J}$ that values greater than $40 \mathrm{nmol} / 1(16 \mathrm{ng} / \mathrm{ml})$ are reached in $N$ summer. As none of the people in this study achieved this $D$ concentration in summer it would be interesting to know how the absolute time that elderly people spend out of doors compares with that of younger people.

In this and our previous study the times of the peaks of $\omega$ plasma 25-OHD concentrations and daily UVL did not coincide. The maximum values were reached at the same time of

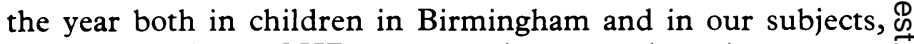
even though the 25-OHD concentrations were three times greater in the children than the old people. The simplest explanation of this non-coincidence is that people's individual exposure to $\overrightarrow{\mathbb{D}}$ UVL does not parallel exactly its availability-for example, $\frac{?}{\mathbb{D}}$ people tend to have annual holidays in August, which will delay $\frac{0}{\sigma}$ the time of their maximum exposure to UVL until after the time when the daily UVL reaches its maximum.

Two attitudes to these findings may be taken. Firstly, plasma 25-OHD concentrations in the elderly appear to be extremelyō low in winter and presumably should be raised. According to $?$ the established view our findings show that dietary vitamin $\mathrm{D}$ intakes are inadequate and the fortification of food with vitamin $D$ should be at a higher level than that currently practised with margarine. Our results indicate that the mean intake for the 
population of the $\mathrm{UK}$ should be raised to about $5 \mu \mathrm{g} /$ day in order that the elderly and others with a limited intake of dietary vitamin $\mathrm{D}$ and with infrequent exposure to UVL reach a minimal acceptable vitamin D state. Such a state is that sufficient to prevent the occurrence of osteomalacia, which would require plasma 25-OHD concentrations of 7.5-10.0 nmol/1 (3-4 ng/ml). Although fatty fish (for example, sardines) and Ovaltine could provide $5 \mu \mathrm{g}$ of vitamin $\mathrm{D} /$ day if consumed frequently, they are not widely eaten and therefore some other foodstuff requires to be fortified.

The alternative view of these findings accepts that the vitamin $\mathrm{D}$ state of the British population as a whole is undoubtedly adequate for normal health due virtually entirely to solar UVL. The contribution of dietary vitamin $\mathrm{D}$ is unimportant compared with the effects produced by UVL (plasma 25-OHD concentrations of 50-75 nmol/1 (20-30 ng/ml)). Even if a dietary vitamin $\mathrm{D}$ intake of $5 \mu \mathrm{g}$ was accepted as the minimum recommended, however, rather than an intake equivalent to the UVL received by the British (about $50 \mu \mathrm{g} / \mathrm{day}^{5}$ ), such levels would be impossible to reach without fortification given the low concentration at which this substance occurs in food. Physiologically, therefore, vitamin $\mathrm{D}$ is an essential metabolite with the rare property of being formed by UVL rather than an enzyme, and should not be regarded as a nutrient. This conclusion has obvious implications, but the recent successful efforts ${ }^{23}$ to improve the vitamin D state of the elderly using UVL are to be welcomed as being the more physiological approach. Although UVL may be harmful to skin, only small quantities at wavelengths of $300-310 \mathrm{~nm}$ are required to produce vitamin D.

We are indebted to the subjects for their participation in this study, and to the nutrition field-workers Miss E Allen and Mrs E Muncaster, and the nurse Mrs K Hodgson. We also thank Mr J Ashford for the 25-OHD assays and Mr K Day for the computer data analysis.

\section{References}

1 Quarterman, J, Dalgarno, A C, and Adam, A, British fournal of Nutrition, 1964, 18, 79 .

2 Jones, G, Clinical Chemistry, 1978, 24, 287.

3 Chick, H, et al, Lancet, 1922, 2, 7.

4 Stamp, T C B, Proceedings of the Nutrition Society, 1975, 34, 119.

5 Stamp, T C B, Haddad, J G, and Twigg, C A, Lancet, 1977, 1, 1341.

- Somerville, P J, Lien, J W K, and Kaye, M, fournal of Gerontology, 1977, 32, 659.

${ }^{7}$ Poskitt, E M, Cole, T, and Lawson, D E M, British Medical fournal, 1979, $1,221$.

8 Stamp, T C B, and Round, J M, Nature, 1973, 247, 563.

9 Schmidt-Gayk, H, et al, Atherosclerosis, 1977, 26, 55.

${ }^{10}$ Pettifor, J M, Ross, F P, and Solomon, L, Lancet, 1978, 1, 827.

11 Neer, R, et al, Proceedings of $3 r d$ Workshop on Vitamin D, ed A W Norman, p 595. Berlin, de Gruyter, 1977.

12 Hunt, S P, et al, British Medical fournal, 1976, 11, 1351.

13 Department of Health and Social Security, A Nutrition Survey of the Elderly, Reports on Health and Social Subjects, No 3. London, DHSS, 1972.

14 Rutishauser, I H E, et al, British fournal of Nutrition. In press.

${ }^{15}$ Edelstein, S, et al, Clinical Science and Molecular Medicine, 1974, 46, 231.

${ }_{16}$ Paul, A A, and Southgate, D A T, McCance and Widdowson's The Composition of Foods, 4th edn. London, HMSO, 1978.

17 Department of Health and Social Security, unpublished information.

18 Johnson, F S, Mo, T, and Green, A E S, Photochemistry and Photobiology, 1976, 23, 179.

19 Lund, B, Sorenson, O H, and Christenson, A B, Lancet, 1975, 2, 300.

20 Corless, D, et al, Lancet, 1975, 1, 1404.

21 Preece, M A, Quarterly Fournal of Medicine, 1975, 44, 575.

${ }^{22}$ Davie, M, Lawson, D E M, and Jung, R T, Lancet, 1978, 1, 820.

${ }^{23}$ Corless, D, et al, Lancet, 1978, 2, 649.

(Accepted 22 fune 1979)

\section{SHORT REPORTS}

\section{$Q$ fever treated with erythromycin}

In-vitro studies of the susceptibility of Coxiella burnetii to antibiotics suggest that only tetracycline and chloramphenicol are effective in $\mathrm{Q}$ fever. ${ }^{1} \mathrm{Q}$-fever endocarditis has been treated successfully with lincomycin, ${ }^{2}$ however, and trimethoprim and sulphamethoxazole may be effective for chronic infections. ${ }^{3}$ Acute $Q$ fever is usually selflimiting and often goes undiagnosed. Even when $Q$ fever is a serious illness the diagnosis may be retrospective. Treatment is given for a non-specific, non-bacterial pneumonia. We report a case of severe $Q$ fever that occurred during a local outbreak. Although the infection was initially misdiagnosed, the patient responded dramatically to intravenous erythromycin.

\section{Case report}

A 25-year-old insulation installer came to the emergency room complaining of anterior right-sided pleuritic chest pain, chills, and nausea. He had been in good health until two days before, when his symptoms began. He had no history of cough, foreign travel, or contact with anyone ill. He owned several dogs and a cat and kept poultry.

Examination showed an acutely ill man with temperature $37.5^{\circ} \mathrm{C}$, pulse $84 / \mathrm{min}$, and respiration $28 / \mathrm{min}$ and shallow. Pertinent findings were mild, diffuse abdominal tenderness without localising signs. His packed cell volume was $0.51(51 \%)$ and white cell count $9.5 \times 10^{9} / 1\left(9500 / \mathrm{mm}^{3}\right)(80 \%$ segmented polymorphonuclear leucocytes, $7 \%$ band cells, $11 \%$ lymphocytes, $2 \%$ monocytes). Erythrocyte sedimentation rate was $48 \mathrm{~mm}$ in the first hour. A chest radiograph showed bilateral infiltrates in the right-middle and leftupper lobes.

The patient was admitted for observation, and immediately his temperature spiked to $40^{\circ} \mathrm{C}$. We considered diagnoses of legionnaire's disease, mycoplasma pneumonia, psittacosis, and viral pneumonia. Because of his chest $x$-ray appearances, age, exposure history (work and home), and severe nausea, after routine specimens of sputum and urine were taken for culture he was given intravenous erythromycin lactobionate, $500 \mathrm{mg}$ six-hourly. After 48 hours he was greatly improved; his temperature was $38^{\circ} \mathrm{C}$, and his chest radiograph showed partial clearing. All the bacterial cultures were sterile Meanwhile, his wife and three close friends were admitted to hospital with pneumonia. All improved dramatically after 48 hours of intravenous erythromycin. A serological diagnosis of $Q$ fever was made retrospectively in all five patients. The most complete data were available for the index case (table).

Results of serological tests (expressed as reciprocal of dilution) on serum specimens ( $S 1$ and $S 2$ collected three weeks apart) from index case of $Q$ fever

\begin{tabular}{|c|c|c|c|c|c|c|c|}
\hline \multicolumn{6}{|c|}{ Test } & \multirow{2}{*}{$\frac{S 1}{128}$} & \multirow{2}{*}{$\frac{\mathrm{S} 2}{128}$} \\
\hline Complement & xation & .. & . & .. & .. & & \\
\hline $\begin{array}{c}\text { Microagglut } \\
\text { Phase I } \\
\text { Phase II }\end{array}$ & $\begin{array}{c}\text { tion } \\
\therefore \\
\therefore\end{array}$ & 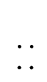 & 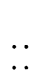 & $\because$ & 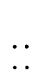 & $\begin{array}{r}<4 \\
4096\end{array}$ & $\begin{array}{r}32 \\
2048\end{array}$ \\
\hline $\begin{array}{c}\text { Indirect imm } \\
\text { Phase I } \\
\text { IgM . . } \\
\text { IgG .. }\end{array}$ & $\begin{array}{l}\text { nofluor } \\
\qquad . \\
\ldots\end{array}$ & $\begin{array}{l}\text { escer } \\
\quad \ldots \\
\cdots\end{array}$ & $\therefore$ & $\because$. & $\therefore$ & $\begin{array}{r}32 \\
<8\end{array}$ & $\begin{array}{l}64 \\
64\end{array}$ \\
\hline $\begin{array}{c}\text { Phase II } \\
\text { IgM... } \\
\text { IgG .. }\end{array}$ & 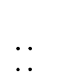 & .. & 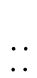 & 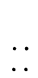 & .. & $\begin{array}{r}1024 \\
256\end{array}$ & $\begin{array}{r}2048 \\
16384\end{array}$ \\
\hline
\end{tabular}

\section{Comment}

The diagnosis of $\mathrm{Q}$ fever is more often missed in the United States (and reported as pneumonia) than in areas where the disease is more common. This probably results from recognising only the most serious cases. All our patients had pneumonia, high fever, and abdominal symptoms. We therefore assumed that their illnesses were more severe than usual and gave antibiotics.

The variable course of $Q$ fever makes assessment of the effect of any antibiotic difficult. In all patients with $Q$ fever, treated and untreated, fever usually lasts more than seven days. Treatment with penicillin does not reduce the duration of fever, and even appropriate antibiotics 